\title{
Cemento-osseous dysplasia: a diagnostic challenge
}

SADJ May 2019, Vol. 74 No. 4 p200 - p202

CEE Noffke ${ }^{1}$, EJ Raubenheimer², V Peranovic ${ }^{3}$

\section{SUMMARY}

Cemento-osseous dysplasia is the most common fibroosseous lesion affecting the jaw bones. Due to the potential risk of introducing an infection, biopsy of an asymptomatic lesion is contra-indicated and it is therefore mandatory to establish an accurate diagnosis only on clinical and radiological information. In order to achieve this, a thorough knowledge of the clinical manifestations of cemento-osseous dysplasia together with the pertinent radiological features is required.

This paper is aimed at providing oral health practitioners with the diagnostic features and clinical differential diagnosis of the spectrum of lesions categorised as cemento-osseous dysplasia.

\section{INTRODUCTION}

Cemento-osseous dysplasia (COD) is defined by the World Health Organization (WHO) as "a non-neoplastic fibro-osseous lesion of the tooth-bearing regions of the gnathic bones". ${ }^{1}$ It is generally accepted as the most common benign fibro-osseous lesion affecting the jaw bones. ${ }^{1,2}$ Uncomplicated cases are asymptomatic and discovered as incidental findings on dental radiographs. In order to prevent infection of a lesion, a surgical biopsy is not advised. ${ }^{2}$ It is therefore important to accurately diagnose COD by employing a non-invasive approach.

To this end a thorough knowledge of the radiological manifestations of COD and the lesions considered in its differential diagnosis is obligatory. The aim of this manuscript is to provide oral health care workers with the competency to diagnose COD and to manage the lesions appropriately.

\section{Author affiliations:}

1. Claudia EE Noffke: MSc., Private Consultant and Guest Professor, KUL Belgium.

ORCID Number: 0000-0001-5842-8446

2. Eric J Raubenheimer: $P h D, D S c$., Senior Consultant Ampath, Guest Professor KUL Belgium, Extraordinary Professor, Department of Oral Pathology and Oral Biology, University of Pretoria. ORCID Number: 0000-0003-0554-2389

3. Vlasta Peranovic: MDS , Lecturer, Department of Maxillofacial and Oral Radiology, School of Oral Health Sciences, Sefako Makgatho Health Sciences University, South Africa.

Corresponding author: Claudia EE Noffke

248 Argo Place, Waterkloof Ridge, Pretoria, 0181.

Email: claudia@fox5.co.za

Author contributions:

1. Claudia EE Noffke: Principal author, writing of manuscript - $60 \%$, provision of images - $40 \%$

2. Eric $J$ Raubenheimer: Writing of manuscript - $25 \%$, provision of images - $20 \%$

3. Vlasta Peranovic: Writing of manuscript - $15 \%$, provision of images - $40 \%$

\section{ACRONYMS}

COD: Cemento-Osseous Dysplasia

WHO: World Health Organization

\section{CLINICAL MANIFESTATION}

On the basis of anatomical distribution, COD's manifest with three variants: focal-, florid- and periapical types. Focal COD is a single lesion with a predilection for females and the posterior mandible,,,$^{3,4}$ florid COD manifests with lesions involving more than one jaw quadrant ${ }^{5,6}$ and periapical COD is located in the periapical regions of mandibular incisor teeth. ${ }^{2}$ Florid- and to a lesser extent periapical COD's have a tendency to be associated with simple bone cysts. ${ }^{5-7}$ All variants are asymptomatic and although sporadic cases have been reported in Caucasians, it is middle-aged to elderly Black- and Asian females are primarily affected. ${ }^{8-11}$

The epicentre of all types is the alveolar bone close to the apices of vital teeth and uncomplicated mature lesions manifest without tooth displacement or root resorption and no- or minimal expansion. ${ }^{2,5}$ Most COD's only become symptomatic when secondarily infected.

\section{PATHOGENESIS AND PATHOLOGY}

All types of COD are characterized by mineralized tissue which, with advancing maturity, replaces the fibrous component centrifugally ${ }^{2}$ (from the centre towards the periphery of the lesion) (Figure 1). All lesions mature into hypocellular, mineralized lobular masses (frequently described as a ginger root-like masses ${ }^{12,13}$ ) and cease to enlarge when this stage is reached.

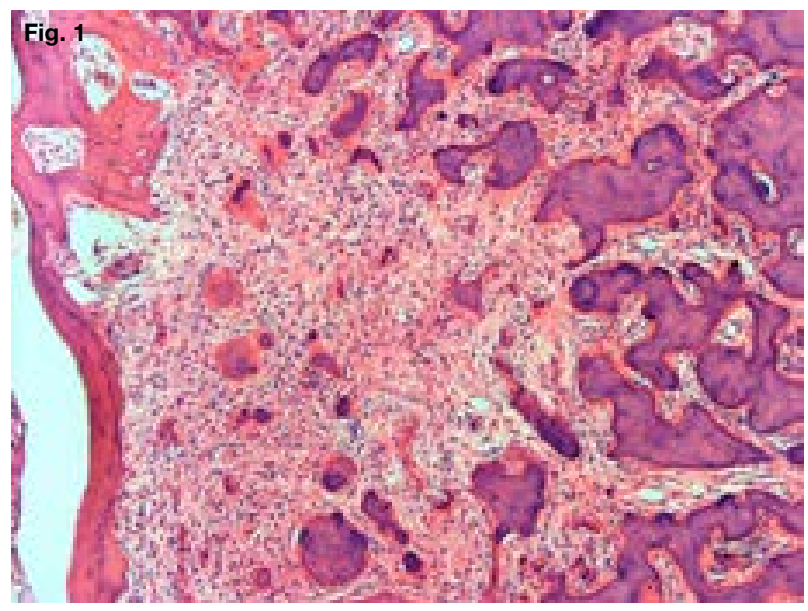

Figure 1. Micrograph of a $C O D$ showing the mature central part which consists of globular calcifications (right side of image) and the peripheral zone of fibrous tissue on the left side of the image (H\&E stain, X100). 
Antibiotic treatment of an infected mature COD is severely compromised by the poor blood flow through the lesion, which subsequently invariably sequestrates.

The periodontal ligament space is not involved by a COD and unlike proliferations of dental cementum, the lesion is not attached to the root surface of the associated tooth or teeth.

Several authors view the dense mineralized tissue as bone and not cementum because of the separation from the root surface and question the use of "cemento" in the terminology pertaining to the condition.,

The development of a simple bone cyst, which occurs more frequently in florid COD than in the other types, is due to the initiation of foci of resorption of the mineralized tissue. This results in the development of nonepithelial lined cavities which ultimately fuse, creating a large multilocular space which is visible on radiographs.

\section{RADIOLOGY}

Focal-, florid and periapical osseous dysplasias (COD's) share similar radiological features and are distinguished by the location and distribution of the lesion(s). Separation of the COD from the root surface by an uninvolved periodontal ligament space can be demonstrated radiographically.

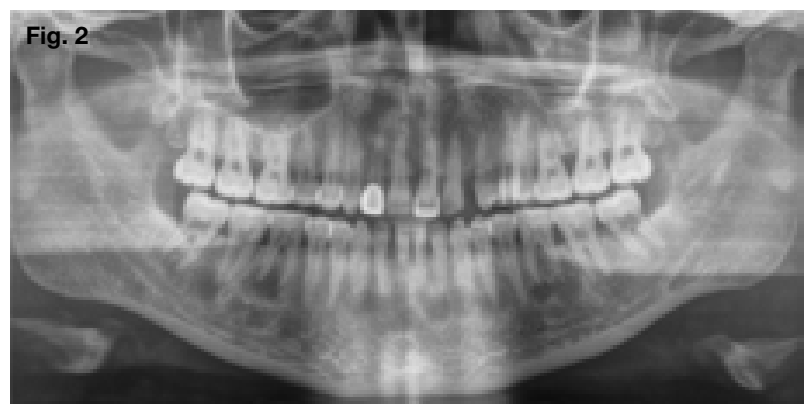

Figure 2. Panoramic image showing the radiolucent stage of florid COD Note the radiolucencies in the periapical regions of several asymptomatic vital mandibular teeth.
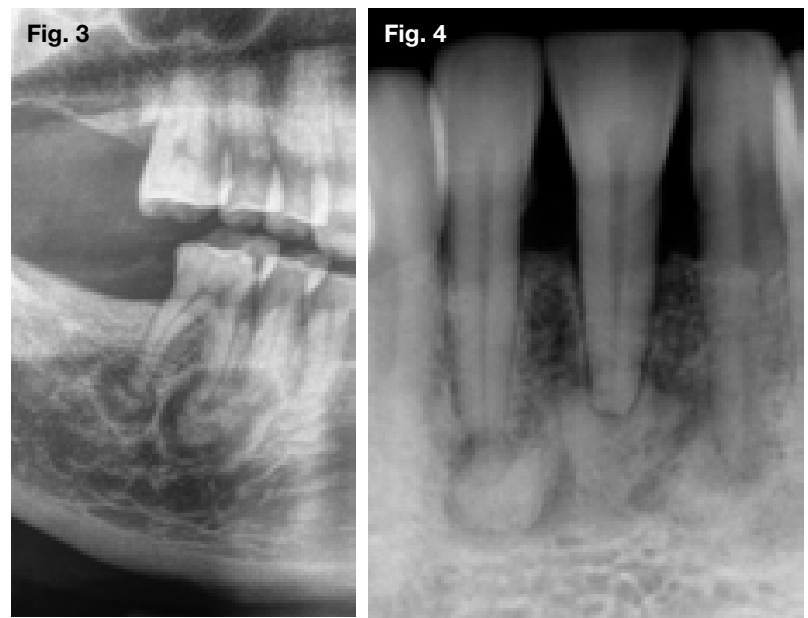

Figure 3. Cropped panoramic image showing the mixed radiopaque stage of a focal COD associated with a mandibular first molar tooth. Note the central lobulated radiopacities surrounded by a radiolucent rim.

Figure 4. Radiopaque stage of periapical COD. Note the periapical radiopaque masses separated from the apices of vital and asymptomatic mandibular incisors by an uninvolved periodontal ligament space.
Maturation with progressive opacification from the centre outwards is a key feature which underscores the radiological diagnosis of COD. Although the process of maturation is continuous, three stages are generally agreed upon. The predominant fibrous content of the early stage manifests radiologically as well-defined oval to round periapical radiolucencies (Figure 2). The intermediate stage consists of a mixture of fibrous- and mineralized tissues and presents with a mixed radiolucent-radiopaque internal structure (Figure 3).

The characteristic central lobular radiopacities are surrounded by a radiolucent zone of varying width which corresponds to the maturity of the lesion. In the intermediate stage, the lesion is well-defined and may show a sclerotic border, which indicates reactive bone associated with the slow rate of enlargement. Mature lesions cease to enlarge and present as lobular radiopaque masses with a narrow radiolucent border (Figure 4).

The multiple lesions of periapical- and florid COD may become confluent in all stages. Simple bone cysts manifest radiologically as uni- or multilocular radiolucencies which may cause cortical expansion (Figure 5).

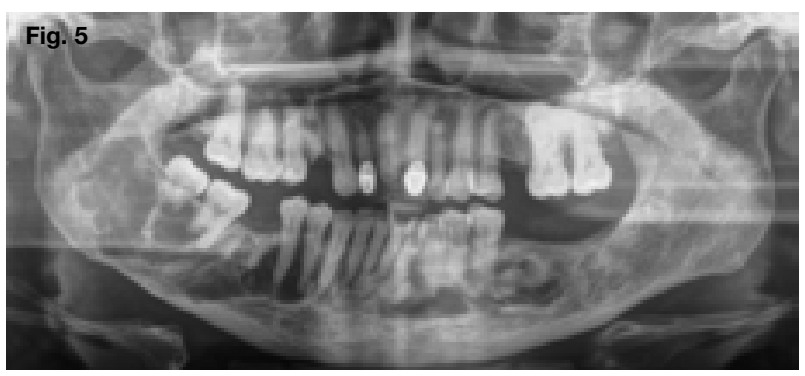

Figure 5. Panoramic image of florid COD (mixed radiopaque stage). Note the simple bone cysts manifesting as multilocular cavities in the right mandibular premolar and molar regions.

Transition of the lobular radiopacities into sharply pointed structures indicates infection which is frequently associated with pain, sequestration, root resorption and tooth displacement.

Mature lesions which are not infected and located in edentulous areas may show migration towards the alveolar crest where they may be exposed to the oral environment and become infected (Figure 6). Although resorption of the edentulous alveolar process may contribute to the change in the relative position of the lesion, the reasons for the migration are speculative.

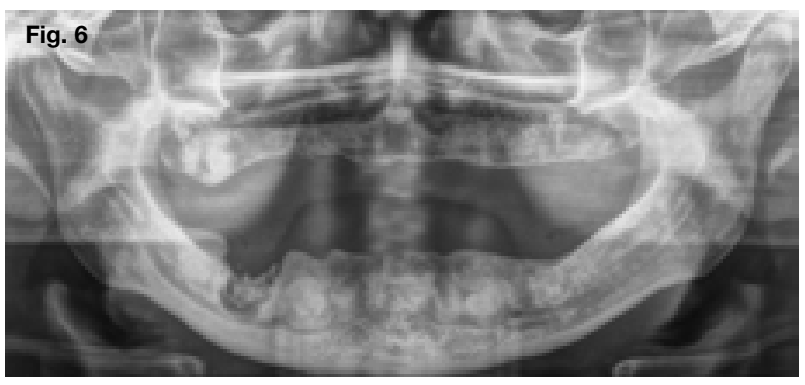

Figure 6. Panoramic image of a mature florid COD in an edentulous mandible. Note the broad radiolucent border and pointed radiopacities in the right mandibular molar area which indicate secondary infection with sequestration in contrast to the non-infected mature lesions in the left mandible which manifest as lobular radiopacities. 


\section{DIFFERENTIAL DIAGNOSIS}

The main distinguishing features of lesions and conditions which closely resemble COD on dental radiographs are reflected in Table 1.

\begin{tabular}{|c|c|}
\hline Lesion/ condition & Main differentiating features from COD \\
\hline \multicolumn{2}{|r|}{ Radiolucent stage } \\
\hline $\begin{array}{l}\text { Periapical inflammatory } \\
\text { disease (periapical radicu- } \\
\text { lar cyst and granuloma) }\end{array}$ & $\begin{array}{l}\text { Always associated with a non-vital tooth, }{ }^{2} \text { involves the } \\
\text { periodontal ligament, signs of external root resorption in } \\
\text { chronic cases. }\end{array}$ \\
\hline $\begin{array}{l}\text { Osteoporotic bone } \\
\text { marrow space }\end{array}$ & $\begin{array}{l}\text { Vicinity of mandibular molars, one or more randomly dis- } \\
\text { tributed radiolucencies which fail to mature. }\end{array}$ \\
\hline Multiple myeloma & $\begin{array}{l}\text { Elderly patients, commonly in posterior mandible, multiple } \\
\text { punched-out radiolucencies, monoclonal protein peak } \\
\text { in serum. }\end{array}$ \\
\hline $\begin{array}{l}\text { Primary hyperparathy- } \\
\text { roidism }\end{array}$ & $\begin{array}{l}\text { Multiple random skeletal radiolucencies, generalized os- } \\
\text { teopenia, usually associated with kidney disease. }{ }^{14}\end{array}$ \\
\hline \multicolumn{2}{|c|}{ Mixed radiolucent-radiopaque stage } \\
\hline Ossifying fibroma & $\begin{array}{l}\text { Mandibular molar region, expansive growth with bowing of } \\
\text { inferior mandibular cortex, }{ }^{15} \text { growth in centrifugal pattern, } \\
\text { tooth displacement and root resorption, fails to show signs } \\
\text { of maturation, removed with relative ease. }\end{array}$ \\
\hline $\begin{array}{l}\text { Focal sclerosing osteo- } \\
\text { myelitis }\end{array}$ & $\begin{array}{l}\text { Associated with dental infection, irregular and ill-defined, } \\
\text { blends into adjacent normal bone, no radiolucent border. }\end{array}$ \\
\hline $\begin{array}{l}\text { Diffuse chronic sclerosing } \\
\text { osteomyelitis }\end{array}$ & $\begin{array}{l}\text { Diffuse irregular mixed lesions associated with periodontal } \\
\text { infection or infected florid COD, wider radiolucent border } \\
\text { around radiodensities. }\end{array}$ \\
\hline \multicolumn{2}{|r|}{ Radiopaque stage } \\
\hline Enostosis & $\begin{array}{l}\text { No radiolucent border, blends with the surrounding bone, } \\
\text { outgrowth of cortical bone with thorny projections on axial } \\
\text { CBCT projections, may present bilaterally. }\end{array}$ \\
\hline Odontoma & $\begin{array}{l}\text { Often prevent eruption of a tooth, radiolucent border with } \\
\text { tooth-like structures and outer cortical border. }\end{array}$ \\
\hline Root remnant & Morphology of a root. \\
\hline Cementoblastoma & $\begin{array}{l}\text { Mandibular molars and premolars, mineralized mass at- } \\
\text { tached to root surface, round or oval, frequently pain and } \\
\text { expansion, difficult extraction }\end{array}$ \\
\hline Hypercementosis & $\begin{array}{l}\text { Fusiform widening of cementum attached to root surface, } \\
\text { difficult extraction. }\end{array}$ \\
\hline Paget's disease of bone & $\begin{array}{l}\text { Affects gnathial and extragnathial bones, also located be- } \\
\text { low the inferior alveolar canal, cotton wool appearance, } \\
\text { generalized hypercementosis and loss of lamina dura, ele- } \\
\text { vated blood alkaline phosphatase concentrations. }\end{array}$ \\
\hline
\end{tabular}

\section{MANAGEMENT}

Asymptomatic CODs which are discovered as incidental findings on radiographs require no management except for the prevention of dental infections through regular follow-up, prophylaxis and maintenance of good oral hygiene..$^{2,16,17}$

Secondary infection is usually the result of periapical infective disease, extraction of an associated tooth, an open fracture or a surgical biopsy procedure and is resistant to antibiotics due to failure to achieve therapeutic concentrations in the avascular mineralized tissue of a mature lesion. All invasive surgical procedures in asymptomatic COD, including the extraction of a tooth, should be considered only if other management options have been exhausted.

The placing of an implant in a COD is contra-indicated due to the adverse infective complication which invariably leads to sequestration with implant failure. Unlike cementoblastoma and hypercementosis, where the removal of the involved tooth is complicated by the excessive dental cementum attached to the root surface, the extraction of teeth associated with COD is technically not problematic.

\section{CONCLUSION}

The accurate diagnosis of a COD is the most important step in preventing the devastating complication of infection with sequestration of an asymptomatic lesion. This can only be achieved with an adequate knowledge of the clinical and radiological features of COD.

\section{Conflict of interest}

The authors declared no conflict of interest.

\section{References}

1. Takata T, Slootweg PJ. Odontogenic and maxillofacial bone tumours. In: El-Naggar AK, Chan JKC, Grandis JR, Takata T, Slootweg PJ, eds. WHO Classification of Head and Neck Tumours. Lyon: IARC, 2017:203-60.

2. Brannon RB, Fowler CB. Benign fibro-osseous lesions: a reviewof the current concepts. Adv Anat Pathol. 2001; 8: 126-34.

3. Summerlin DJ, Tomich CE. Focal cemento-osseous dysplasia: a clinicopathologic study of 221 cases. Oral Surg Oral Med Oral Pathol. 1994; 78:611-20.

4. MacDonald-Jankowski DS. Focal cemento-osseous dysplasias: a systematic review. Dentomaxillofac Radiol. 2008; 37: 350-66.

5. Alsufyani NA, Lam EW. Osseous (cemento-osseous) dysplasia of the jaws: clinical and radiographic analysis. J Can Dent Assoc. 2011; 77: b70.

6. Fernandes DT, Pereira DL, Santos-Silva AR, Vargas PA, Lopes MA. Florid osseous dysplasia associated with multiple simple bone cysts: a patient with 22 years of follow-up. Gen Dent. 2016; 64:21-5.

7. Noffke CEE, Raubenheimer EJ, MacDonald DS. Fibro-osseous disease: harmonizing terminology with biology. Oral Surg Oral Med Oral Pathol Oral Radiol. 2012; 114:388-92.

8. MacDonald-Jankowski DS. Florid cemento-osseous dysplasia: a systematic review. Dentomaxillofac Radiol. 2003; 32:141-9.

9. Slootweg PJ. Osseous dysplasias. In: Barnes L, Eveson JW, Reichart P, Sidransky D, eds. Pathology and Genetics of Head and Neck Tumours. Lyon: IARC, 2005:323.

10. Pereira DL et al. Clinical, demographic and radiographic analysis of 82 patients affected by florid osseous dysplasia: an international collaborative study. Oral Surg Oral Med Oral Pathol Oral Radiol. 2016; 122:250-7.

11. Owosho A, Potluri A, Bilcodeau EA. Osseous dysplasia (cemento-osseous dysplasia) of the jaw bones in western Pennsylvania patients: analysis of 35 cases. Pa Dent J. 2013; 80:25-9.

12. Su L, Weathers DR, Waldron CA. Distinguishing features of focal cemento-osseous dysplasia and cemento-ossifying fibromas: I. A pathologic spectrum of 316 cases. Oral Surg Oral Med Oral Pathol Oral Radiol Endo. 1997; 84:301-9.

13. Su L, Weathers DR, Waldron C. Distinguishing features of focal cemento-osseous dysplasia and cemento-ossifying fibromas. II. A clinical and radiologic spectrum of 316 cases. Oral Surg Oral Med Oral Pathol Oral Radiol Endo. 1997; 84:540-9.

14. Raubenheimer EJ, Noffke CEE, Hendrik HD. Chronic kidney disease-mineral bone disorder: an update on the pathology and cranial manifestations. J Oral Pathol Med. 2015:239-43.

15. Jundt G. Fibrous dysplasia. In: Barnes L, Eveson JW, Reichart P, Sidransky D, eds. Pathology and Genetics of Head and Neck Tumours. Lyon: IARC Press, 2005:319-20.

16. 16. Mahalingam G, Manoharan GV. Florid osseous dysplasia-report of two cases and review of literature. J Clin Diagn Res. 2017; 11:ZD21-ZD24.

17. Aiuto R, Gucciardino F, Rapetti R, Siervo S, Bianch AE. Management of symptomatic florid cemento-osseous dysplasia: Literature review and a case report. J Clin Exp Dent. 2018; 10:e291-e95. 